\title{
A fome na exclusão social em São Paulo nos anos 2000
}

\author{
Arquias Sófocles Guimarães Soares Cruz
}

\begin{abstract}
Resumo
A fome é um problema social que afeta milhões de pessoas no Brasil, mas muitas vezes faltam discussões sobre sua dimensão política no contexto histórico da América Latina. Nesse sentido, os estudos sobre a fome devem envolver mais questões do que apenas renda, por se tratar de uma questão multidimensional, levantando a questão das várias opressões sofridas pela população excluída da sociedade. Na perspectiva decolonialista de Quijano, o artigo analisa a relação entre exclusão social e fome no Estado de São Paulo na década de 2000, período de considerável desenvolvimento social. Tentou-se discutir alguns fatores políticos relevantes para a compreensão da fome como um processo social, por exemplo, a colonialidade do poder na América Latina. Para isso, os dados utilizados foram o Índice de Vulnerabilidade Social do IPEA e algumas estatísticas da Pesquisa Nacional por Amostra de Domicílios (PNAD Segurança Alimentar 2004/2009) do IBGE. Conclui-se que existem padrões semelhantes no comportamento dos dados e que há recorrência de alguns temas, como desigualdades de gênero e raça, embora os índices gerais tenham apontado avanços sociais ao longo da década. Palavras-chaves:colonialidade do poder, exclusão social, fome.
\end{abstract}

\begin{abstract}
Hunger is a social problem that affects millions of people in Brazil, but there is often a lack of discussions about its political dimension in the Latin American historical context. In this sense, studies on hunger should involve more questions than just income, because it is a multidimensional issue, raising the question of the various oppressions suffered by the excluded people in society. From the decolonialist perspective of Quijano, the article analyses of the relationship between social exclusion and hunger in the State of São Paulo in the 2000s, a period of considerable social development. We sought to discuss some political factors relevant to the understanding of hunger as a social process, for example the coloniality of power in Latin America. For that, the data used were the IPEA Social Vulnerability Index and some statistics from the Pesquisa Nacional por Amostra de Domicílios (PNAD Food Security 2004/2009) of the IBGE. It was concluded that there are similar patterns in data behaviour and that there is a recurrence of some themes, such as gender and racial inequalities, although general indices have pointed to social advances during the decade. Keywords: coloniality of power, social exclusion, malnutrition.
\end{abstract}

*Bacharelando em Ciências e Humanidades na UFABC - contato: arquiassofocles2@gmail.com 


\section{Introdução}

Quando se discute sobre os problemas sociais na América Latina, é preciso considerar as estruturas sociopolíticas presentes ao longo da história da região. Isso nos permite uma compreensão contextualizada dos processos sociais para, então, analisarmos os seus índices. Entre os problemas que afetam a América Latina, a fome mostra-se como um dos mais relevantes por comprometer não só a qualidade de vida das pessoas, mas também a própria sobrevivência delas.

Trazendo o tema à realidade do nosso país, é chamativo que o Brasil deixou de aparecer no Mapa da Fome da Organização das Nações Unidas para Agricultura e Alimentação (FAO) em 2014 e, no entanto, já encontra-se ameaçado a voltar a essa situação crítica desde 2017 , no contexto da crise econômica e política, que reduziu as políticas sociais que haviam sido implementadas desde o início dos anos 2000. Desse modo, é importante discutirmos a dimensão política da fome e o seu cenário na primeira década dos anos 2000, na qual houve uma redução de seus índices nacionais. Segundo Josué de Castro (1952), um dos autores clássicos no tema da fome no Brasil, há uma forte relação entre a fome orgânica (entendida não só como a aguda ou extrema, mas numa escala de subnutrição com impactos variados sobre o corpo devido a carências de vitaminas, por exemplo) com a dimensão sociopolítica das epidemias de fome.

Josué de Castro (1952) analisa as causas desse processo social no cenário de desigualdades e de conflitos em meados do século XX. O autor nos mostra como este debate das fomes orgânicas dialoga com aspectos marcantes da estrutura social e produtiva brasileira, que é de uma matriz colonial. Décadas após as contribuições do autor, a fome tem persistido como um problema de grande escala para a população brasileira, pois, mesmo no período no qual houve grandes políticas públicas para combatê-la, não foi possível erradicá-la.

Evidentemente, a primeira década do século XXI representou um avanço socioeconômico imenso aos países da América Latina. O crescimento econômico, durante o período de "inflexão à esquerda", gerou aumento produtivo, redução das desigualdades e melhoria social através de políticas públicas (ZANATTA, 2017). De acordo com dados da FAO, a prevalência da subalimentação no Brasil diminuiu em aproximadamente um quarto no período dos anos 2000. Mas, o número total permaneceu alto, atingindo 5 milhões de pessoas ao final de 2010 (FAO, 2016-2019).

Na literatura sobre $o$ assunto, é comum encontrarmos estudos apontando que um dos seus principais fatores contemporâneos é a falta de renda para a compra de alimentos. No entanto, isso não é suficiente para se explicar a fome como um processo social. Apesar do debate ter superado, em parte devido às contribuições de Josué de Castro, as perspectivas que naturalizaram a fome ou reduzem-na à dimensão biológica, ainda é preciso analisá-la como um processo fruto da história da sociedade brasileira, conforme mencionado acima.

Nesse sentido, também se recorre à obra de Aníbal Quijano, um dos principais autores da perspectiva decolonial, uma corrente nas ciências sociais que discute sobre as consequências da colonização para a trajetória dos povos colonizados e para a

1 Conforme a entrevista dada ao Jornal Nexo pelo economista Francisco Menezes, da Action Brazil. Disponível em https://www.nexojornal.com.br/expresso/2017/07/23/Como-o-Brasil-saiu-do-Mapada-Fome.-E-por-que-ele-pode-voltar. 
forma como elas se perpetuaram nos sistemas político-econômicos dessas sociedades desiguais.

Quijano (2005) explica sobre a colonialidade do poder, um padrão de poder mundial que representa as consequências coloniais na estrutura social e que emergiu da convergência de dois processos históricos: o capitalismo mundializado e o racismo nas Américas. Com isso, consolidou-se o capitalismo colonial/moderno no qual a ideia de raças (usada pelo eurocentrismo para "justificar" a colonização) gerou uma classificação social que hierarquizou os grupos e as identidades e estabeleceu uma sistemática divisão racial do trabalho.

As relações de dominação de raça (e de gênero, que, para o autor é uma questão mais antiga que a dominação racial e que a capitalista) desse período se reproduziram mesmo após as independências. Uma das suas marcas no Brasil pós-colonial é a desigualdade profunda entre pessoas brancas e negras. Conforme a concentração de riqueza evidencia uma estrutura retrógrada e segregatória, percebe-se que há uma exclusão social condiciona diversos problemas sociais.

Partindo da questão sobre a fome no contexto social brasileiro, este artigo pretende relacioná-la à exclusão social no Estado de São Paulo. Por isso, pergunta-se: como compreender a situação de fome no Estado de São Paulo diante da exclusão social na década de 2000? A hipótese apresentada é a de que o quadro da fome no Estado de São Paulo foi (e é) condicionado por estruturas sociais desiguais presentes historicamente no Brasil. Desse modo, para se analisar a dimensão social da fome, deve-se entender a sua relação com a exclusão social e seus marcos conceituais, já que essa exclusão reproduz uma partilha e aquisição desiguais aos alimentos.

A pesquisa empregada trata-se de uma tentativa exploratória de abordar 0 tema sob a perspectiva decolonial. Ela teve natureza aplicada, visando descrever o panorama da fome em São Paulo e buscando, na medida do possível, apontar a sua interface com a exclusão social. Nesse sentido, a metodologia consiste em uma pesquisa descritiva que é bibliográfica e ex-post-facto, mesclando elementos qualitativos com quantitativos na análise de dados secundários do IBGE.

Além desta introdução, o artigo divide-se em outras três seções. Na segunda seção, se abordará a discussão conceitual sobre a exclusão social e se discutirá sobre os dados do Estado de São Paulo. Na terceira seção, haverá uma definição dos termos do debate sobre a fome e, em seguida, se descreverá e se analisará dados sobre a fome no cenário da exclusão social de São Paulo. Por último, haverá uma síntese dos resultados com algumas questões pontuais para futuras discussões.

\section{Discutindo a exclusão social no Brasil}

Conforme mencionado, a perspectiva decolonial de Quijano nos remete para as especificidades históricas das relações de dominação e exclusão na América Latina. $\mathrm{O}$ autor discute principalmente sobre o conceito de classe, categoria relevante para se pensar exclusão social. Na sua concepção, a classificação social moderna tem raízes no colonialismo. Critica o método do materialismo ortodoxo que privilegia a concepção econômica como monolítica de análise, pois, nas trajetórias das populações oprimidas, tem havido uma heterogeneidade histórico-estrutural das dominações/explorações existentes. Dessa maneira, entende-se que a dimensão econômica no conceito de classe e exclusão social não tem uma primazia em relação a outras estruturas exclu- 
dentes como as raciais e de gênero. Contudo, os três eixos de classificação social na colonialidade do poder - raça, gênero e capital/trabalho - teriam a dimensão econômica como a "articuladora" e a mais constante, dada a colonialidade do poder, que se pauta na divisão racista e machista do trabalho (QUIJANO, 2011).

Isso mostra a relevância do acesso à renda na questão da fome, porém não se mostra suficiente para explicar a totalidade desse processo nem da exclusão social. Embora, na literatura sobre a exclusão social, haja abordagens diversas, pode-se apontar algumas noções subjacentes a esse conceito. Uma primeira noção é a de que a exclusão ressalta as desigualdades da sociedade e faz um contraste com as pessoas que usufruem da inclusão social (ou participação, os termos voltam-se ao acesso aos bens sociais²). Nisso, há uma outra noção: a exclusão contrapõe-se à ideia de cidadania e a ênfase passa a recair sobre a privação de direitos. A não efetivação da cidadania é um assunto que necessário para não se reduzir a questão somente à dimensão legal ou ao estudo sobre a aplicação de normas (REIS, SCHWARTZMAN, 2002).

Já para Sposati (1999), a exclusão surgiu como um conceito que denuncia o não respeito ao ideal de cidadania do Primeiro Mundo na época do Estado de Bem-Estar Social, na qual o Estado deveria promover a integração social e garantir a universalidade dos direitos aos cidadãos. No entanto, a autora critica tal noção, pois considera que a exclusão é uma marca inerente ao processo de produção capitalista, e que tem afetado o Terceiro Mundo de maneira ainda mais intensa (SPOSATI, 1999). Nesse sentido, a autora afirma que,

\begin{abstract}
no caso brasileiro, este patamar de universalidade da cidadania não foi ainda consagrado nem na sociedade nem no Estado. Ressalto bem na sociedade, em primeiro lugar, e no Estado, por consequência. [...] Aqui, a exclusão é uma condição genérica da "não elite", ou a inclusão na sociedade se dá perversamente, através da presença da exclusão como uma condição indigna e desqualificada de vida humana. É este o padrão de convívio hierarquizado vigente (SPOSATI, 1999, p. 4-5).
\end{abstract}

Desse modo, nota-se como a discussão sobre exclusão foi, em certa medida, "importada" do contexto dos países centrais, o que não condiz com a realidade do Sul Global, já que a pauta do pertencimento ou participação políticos nunca se aproximaram de uma efetivação para a grande maioria da população. Nessa importação do debate, deve-se evitar a reprodução do eurocentrismo e da falsa universalidade (que põe como regra geral o que foi a experiência para um sujeito dominante socialmente) (PERONA, 2001). A globalização econômica afetou as sociedades de maneiras distintas, sendo mais desigual nas periferias.

Por fim, uma última noção refere-se à relação com a pobreza, o que destaca novamente a relevância da dimensão econômica. O debate sobre exclusão está relacionado ao de pobreza (e de marginalidade), crescendo após a década de 1980. Ambos os conceitos foram se modificando e adquirindo tons mais multidimensionais rompendo com o "reducionismo" econômicd ${ }^{3}$. Contudo, nos estudos sobre exclusão social

2 No artigo "A pobreza e a exclusão social: teorias conceitos e políticas sociais em Portugal." (RODRIGUES, et al,. 2017), há uma interessante resenha teórica sobre os marcos conceituais para distinguir a inclusão da integração e a exclusão social das pobrezas.

3 Principalmente após as contribuições de Amartya Sen à discussão sobre pobreza e desenvolvimento humano. 
no Brasil, tem-se tido um maior foco no desemprego e na concentração de riqueza, mesmo em análises mais históricas sobre os impactos do colonialismo (FRAGOSO, 2002).

Como discutido por Perona (2001), a exclusão social não é um binarismo, mas uma categoria de análise contínua e relativa ao seu contexto histórico e espacial, tendo complemento com o conceito de vulnerabilidade social, e afirma que "en este sentido el concepto de vulnerabilidad refiere a aquella diversidad de 'situaciones intermedias' y al proceso por el cual se está en riesgo de engrosar el espacio de exclusión" (PERONA, 2001, p.15).

Esses conceitos apontam para o acúmulo de desigualdades que, historicamente, impediram a realização da cidadania (embora seja um parâmetro do Norte Global) no cenário de problemas relacionados à pobreza do Sul Global. Desse modo, considera-se aqui que a seguinte definição pode retratar mais adequadamente algumas relações estruturais na sociedade brasileira: "o conceito de exclusão social hoje se confronta diretamente com a concepção de universalidade e com ela a dos direitos sociais e da cidadania. A exclusão é a negação da cidadania" (SPOSATI, 1999, p. 3).

A exclusão social e a vulnerabilidade requerem uma análise com enfoque econômico, mas também com atenção às outras questões de direitos sociais e de raça e de gênero. O Instituto de Pesquisa Econômica Aplicada (IPEA) apresenta dados relativos a essas categorias em seu site da plataforma do Atlas da Vulnerabilidade Social $4^{4}$

Nesse Atlas, tem-se a comparação entre a situação socioeconômica do Estado de São Paulo entre 2000 e 2010. Para tanto é empregado o Índice de Vulnerabilidade Social (IVS), que é medido da seguinte maneira:

O IVS é um índice que varia entre 0 e 1 . Quanto mais próximo a 1, maior é a vulnerabilidade social de um município (figura 1). Para os municípios que apresentam IVS entre 0 e 0,200 , considera-se que possuem muito baixa vulnerabilidade social. Valores entre 0,201 e 0,300 indicam baixa vulnerabilidade social. Aqueles que apresentam IVS entre 0,301 e 0,400 são de média vulnerabilidade social, ao passo que, entre 0,401 e 0,500 são considerados de alta vulnerabilidade social. Qualquer valor entre 0,501 e 1 indica que o município possui muito alta vulnerabilidade social" (COSTA; MARGUTI, 2015, p. 18).

Segundo Costa e Marguti (2015), o país conseguiu diminuir a sua vulnerabilidade social em $27 \%$ na primeira década de 2000. No Estado de São Paulo, é perceptível a redução da exclusão social através da Tabela 1.

Entende-se, baseando-se nesses indicadores multidimensionais, que a vulnerabilidade e a exclusão social decaíram bastante no período entre 2000 e 2010,

4 Nessa plataforma, é possível acessar os dados referentes aos indicadores do IPEA para a exclusão e vulnerabilidade social nas escalas dos municípios, dos estados e de algumas regiões metropolitanas. Utilizaram-se dos dados do IBGE de 2000 e de 2010 e seguem uma metodologia própria baseada em três dimensões: IVS Infraestrutura Urbana, IVS Capital Humano (com foco em educação e saúde para a inclusão social) e IVS Renda e Trabalho. Usaram de dados sobre analfabetismo, renda, mortalidade infantil, serviço de saneamento básico, de mães chefes de família, sem fundamental completo e com filho menor de 15 anos de idade, taxa de desocupação da população de 18 anos ou mais de idade, Índice de Gini entre outros tantos que se tratam de diversos fatores socioeconômicos, conforme discutido na conceituação teórica acima. 
Tabela 1 - Vulnerabilidade social no Estado de São Paulo

\begin{tabular}{|l|l|l|l|}
\hline Sexo & Cor & Ano & IVS \\
\hline Total Sexo & Total Cor & 2000 & 0.388 \\
\hline Total Sexo & Total Cor & 2010 & 0.297 \\
\hline Total Sexo & Negro & 2000 & 0.461 \\
\hline Total Sexo & Negro & 2010 & 0.331 \\
\hline Total Sexo & Branco & 2000 & 0.365 \\
\hline Total Sexo & Branco & 2010 & 0.271 \\
\hline Mulher & Total Cor & 2000 & 0.410 \\
\hline Mulher & Total Cor & 2010 & 0.307 \\
\hline Mulher & Negro & 2000 & 0.471 \\
\hline Mulher & Negro & 2010 & 0.351 \\
\hline
\end{tabular}

FONTE: Adaptação autoral baseada no Atlas de Vulnerabilidade Social (2015).

chegando à categoria baixa. Porém, ao se comparar por raça, nota-se como a exclusão social persistiu em um nível mais acentuado entre a população negra, que já estava na classificação de vulnerabilidade alta (0.461) e passou somente para a vulnerabilidade média (0.331); enquanto a vulnerabilidade entre a população branca teve alteração de média (0.365) para baixa no mesmo período. No caso das mulheres, isso também ocorreu, com mais ênfase nas mulheres negras, que estão na intersecção de opressões de raça e de gênero. Não foi possível comparar com os dados de IVS para homens ("total de cor" ou "branco" ou "negro") pois não houve registros no site para esse recorte específico. De todo modo, observa que, para as pessoas negras e para as mulheres, principalmente para as mulheres negras, os índices de vulnerabilidade social ainda se encontrava em 2010 no patamar médio, embora a vulnerabilidade geral ("totais") tenha diminuído para o patamar baixo. Isso pode ser entendido como um indicativo quantitativo das discussões sobre exclusões de gênero e de raça.

\section{A fome no Estado de São Paulo na década de 2000: dos conceitos aos dados}

Novamente, há a necessidade de se diferenciar os conceitos. Na discussão sobre fome, insegurança alimentar e desnutrição, é útil se começar pela diferenciação feita por Josué de Castro (1952) e pelos parâmetros estabelecidos pela Food and Agriculture Organization (FAO).

Para o autor, a fome não seria apenas a fome aguda ${ }^{5}$, que representaria a extrema fome ou a sensação de carência ou falta de acesso à alimentação constante. Ele compreende que a fome é algo mais amplo em termos sociais e biológicos. Ela incorpora a subnutrição na forma de "fome oculta", na qual pode não haver a sensação de fome urgente, mas há a baixa ingestão de nutrientes necessários para o bom funcionamento do corpo. A fome oculta seria a mais difícil de medir e a mais comum,

5 Para a FAO, o nome desta fome em inglês é hunger, significando a privação de alimentos acompanhada de uma sensação dolorosa. Já malnutrition volta-se ao excesso ou carências no consumo de nutrientes (FAO, 2008). 
visto que, mesmo pessoas com acesso a alimentos diariamente podem ser atingidas por ela (CASTRO, 1952).

Já a FAO utiliza mais "segurança alimentar" após os diversos significados atribuídos ao termo durante os períodos de guerra. A concepção atual está relacionada às soberanias, obrigações (pois há o "direito à alimentação") e capacidades produtivas e comerciais dos Estados-nações de proverem alimentos adequados à sua população. A segurança alimentar abarca quatro dimensões basilares, a saber: disponibilidade física de comida, acesso econômico e físico a alimentos, utilização de alimentos e estabilidade ao longo do tempo das três dimensões anteriores. Para se verificar que há segurança alimentar em uma sociedade, é necessário que todas essas quatro condições estejam contempladas simultaneamente (FAO, 2008).

Nesse sentido, há também a Escala Brasileira de Insegurança Alimentar (EBIA), empregada nas pesquisas da Pesquisa Nacional de Amostra de Domicílios (PNAD), pelo Instituto Brasileiro de Geografia e Estatística (IBGE), que em "edições quinquenais de 2004, 2009 e 2013 utilizou a Escala Brasileira de Insegurança Alimentar (EBIA) [...] A partir dos resultados coletados, a EBIA classifica o nível de insegurança alimentar em quatro graus" (DA SOCIEDADE CIVIL, 2018, p.10).

Os quatro graus incluem segurança alimentar, insegurança alimentar leve, insegurança alimentar moderada e insegurança alimentar grave. Diante das eventuais dificuldades metodológicas na academia de se medir diretamente o processo da fome, essa abordagem da insegurança alimentar tem oferecido um aporte concreto para a análise por índices.

Comparando-se as PNADs de 2004 e 2009 (IBGE, 2010), observa-se que elas registraram uma queda em todos os graus de insegurança alimentar entre $2004 \mathrm{e}$ 2009 no país, havendo aumento de $4 \%$ na distribuição dos domicílios na segurança alimentar para as regiões urbanas. Nas regiões rurais, o seu aumento foi um pouco maior, 8,6\%(DA SOCIEDADE CIVIL, 2018, p.11).

Isso talvez possa ser relacionado aos dados de redução da vulnerabilidade e exclusão social apresentados na seção anterior, indicando uma possível correlação entre ambos os processos sociais, já que apresentaram tendências de diminuição um tanto similares e elementos em comum, como a renda e o desemprego, que foram medidos em ambos os índices analisados.

A redução da fome também foi ao nível nacional (FAO, 2019). No entanto, analisando-se os dados específicos do Estado de São Paulo das mesmas PNADs (IBGE, 2010), ficam mais explícitas novamente as diferenças estruturais entre grupos mais excluídos do que outros no tema da insegurança alimentar (Tabela 2).

As mulheres já estavam em maior quantidade em todos os graus de insegurança alimentar em 2004 e permaneceram em 2010, o que pode apontar novamente indícios das opressões e estruturas desiguais de gênero. Outro ponto é uma aparente mudança da quantidade de pessoas em situação de insegurança alimentar moderada ou grave para a de leve, um sinal positivo apesar da falta de igualdade entre os segmentos de análise.

Já no aspecto racial (Tabela 3), houve proporcionalmente mais insegurança entre as pessoas negras (preta ou parda). Embora haja mais pessoas brancas em domicílios particulares em situação de insegurança alimentar, é notório como as proporções internas em cada população são opostas, ou seja, a grande diferença 
Tabela 2 - Segurança e insegurança alimentar no Estado de São Paulo por gênero.

\begin{tabular}{|l|l|l|l|l|}
\hline Sexo/Ano & Total & $\begin{array}{l}\text { Com se- } \\
\text { gurança } \\
\text { Alimentar }\end{array}$ & $\begin{array}{l}\text { Com Insegu- } \\
\text { rança Alimen- } \\
\text { tar leve }\end{array}$ & $\begin{array}{l}\text { Com Insegurança Ali- } \\
\text { mentar moderada ou } \\
\text { grave }\end{array}$ \\
\hline $\begin{array}{l}\text { Homens } \\
(2004)\end{array}$ & $\begin{array}{l}18 \\
920\end{array}$ & 13715 & 3258 & 1940 \\
\hline $\begin{array}{l}\text { Mulheres } \\
(2004)\end{array}$ & $\begin{array}{l}20 \\
319\end{array}$ & 14790 & 3438 & 2087 \\
\hline $\begin{array}{l}\text { Homens } \\
(2009)\end{array}$ & 20000 & 15047 & 3639 & 1314 \\
\hline $\begin{array}{l}\text { Mulheres } \\
(2009)\end{array}$ & 21062 & 15735 & 3920 & 1407 \\
\hline
\end{tabular}

Fonte: Adaptação autoral baseada no IBGE, 2010.

Tabela 3 - Segurança e insegurança alimentar no Estado de São Paulo por raça.

\begin{tabular}{|l|l|l|l|l|}
\hline Cor/Ano & Total & $\begin{array}{l}\text { Com se- } \\
\text { gurança } \\
\text { Alimentar }\end{array}$ & $\begin{array}{l}\text { Com Inse- } \\
\text { gurança } \\
\text { Alimentar } \\
\text { leve }\end{array}$ & $\begin{array}{l}\text { Com Insegurança Ali- } \\
\text { mentar moderada ou } \\
\text { grave }\end{array}$ \\
\hline $\begin{array}{l}\text { Branca } \\
(2004)\end{array}$ & 27679 & 21491 & 3977 & 2205 \\
\hline $\begin{array}{l}\text { Preta ou } \\
\text { Parda } \\
\text { (2004) }\end{array}$ & 11084 & 6598 & 2676 & 1806 \\
\hline $\begin{array}{l}\text { Branca } \\
(2009)\end{array}$ & 26433 & 20997 & 4199 & 1237 \\
\hline $\begin{array}{l}\text { Preta ou } \\
\text { Parda } \\
\text { (2009) }\end{array}$ & 14010 & 9231 & 3304 & 1475 \\
\hline
\end{tabular}

FONTE: Adaptação autoral baseada no IBGE, 2010.

em quantidades absolutas entre a população branca e a negra reduz muito quando a situação é de insegurança moderada ou grave. Essas análises podem retomar a questão das estruturas históricas que têm impactado mais mulheres e pessoas negras. Por isso, novamente, entende-se que é possível descrever uma forte relação entre os fatores da exclusão social e da fome (ou insegurança alimentar neste caso) no Estado de São Paulo na década de 2000.

\section{A fome na exclusão social}

A primeira década de 2000 no Estado de São Paulo teve dados positivos em termos de redução da exclusão social e da insegurança alimentar. Foi também um período que fez parte da gestão do governo Lula, que elaborou grandes medidas para o combate à fome através do programa Fome Zero, tentando lidar com as principais causas dela: a distribuição desigual dos alimentos, a baixa renda per capita, o custo 
inacessível de vários produtos para as pessoas mais pobres e a tendência ao consumo de alimentos de menor qualidade calórica e nutritiva (ARRUDA, 2007; BELIK, W.; SILVA, J.; TAKAGI, M., 2001).

Como é possível constatar pelas análises dos dados, as tendências um tanto similares e as relações metodológicas entre o IVS e índice de (in)segurança alimentar da PNAD nos evidenciam possíveis correlações entre a fome e a exclusão social. Quanto a essa última, analisou-se como uma compreensão mais ampla nos permitiu captar nuances entre as diferentes populações.

Conforme Quijano (2011) entendia, os fatores da estrutura econômica são os mais constantes nos processos sociais no mundo moderno, mas, isolados, não revelam a totalidade de estruturas desiguais. Por isso, também se deve atentar às questões raciais e de gênero.

Outra dimensão a ser aprofundada mais nas discussões futuras é o aspecto territorial das exclusões, já que o território é um locus de reprodução de desigualdades. Em uma formulação mais ampla, o território é "um espaço definido e delimitado por e a partir relações de poder" (SOUZA, 1995, p. 96). É nele que se reproduzem, concretamente, as estruturas histórico-políticas das sociedades. No caso brasileiro, devemos compreender os impactos do colonialismo e a colonialidade do poder que ainda se mostram presentes na sociedade.

Esse é um movimento similar ao apresentado por Oliveira (2013). A autora retoma a formação territorial brasileira na obra de Caio Prado e Milton Santos e mostra que a situação da fome vem da época colonial com suas relações desiguais e dominadoras, que condicionaram os problemas atuais nas desigualdades socioespacial. Por sua vez, Santos, sintetiza as ideias aqui apresentadas sobre a fome na exclusão social nos territórios brasileiros ao afirmar que,

\footnotetext{
a fome é um dos fenômenos sociais que mais retrata esta produção desigual do espaço. Ou porque ela convive com a abundância e o desperdício em regiões onde a concentração de renda desenha fronteiras, ou porque ela resulta de um modelo de exploração do espaço que esgota todas as possibilidades de garantir a soberania alimentar de comunidades e minorias. Paradoxalmente, a fome nem sempre é produto de uma impossibilidade geográfica, mas provém, sobretudo, como já nos advertira Josué de Castro (2004), de sistemas econômicos e sociais adoecidos. Esta relação mais estreita entre produção capitalista do espaço e fome fica mais evidente quando consideramos o cenário histórico em que certas estruturas econômicas e sociais se formam (SANTOS, 2008, p.3).
}

\section{Conclusão}

Foi apresentada uma breve descrição da relação entre a exclusão social e a fome no Estado de São Paulo, buscando explicitar alguns fatores importantes para a discussão: as estruturas históricas da colonialidade do poder, a multidimensionalidade dos conceitos (com suas diferenciações semânticas) e, brevemente, o território como articulador das relações de desigualdade.

Através da análise do IVS e do índice de insegurança alimentar da PNAD, identificaram-se padrões semelhantes no comportamento dos dados e a recorrência de alguns temas, como as desigualdades de gênero e de raça, mesmo com a diminuição 
significativa dos índices gerais durante a década. Isso dialoga com a definição adotada de exclusão como negação da cidadania e da ideia de universalidade de bem-estar dos sujeitos, ainda mais numa sociedade que jamais teve a integração social de várias "minorias".

A análise dos dados também revelou que a diminuição nos índices de vulnerabilidade e de exclusão social coincidiu com a grande redução da fome, o que pode demonstrar um indício da dimensão político-social argumentava inicialmente.

Contudo, é preciso apontar que a correlação estatística que se pretendia não foi alcançada em sua plenitude, pois não é algo tão direto como se poderia descrever. Trata-se de processos históricos que se entrecruzam com outros fatores conjunturais. $\mathrm{O}$ que se pode afirmar é que essas problemáticas têm ligação com dimensões econômicas (como o desemprego) e, também, com dimensões sociopolíticas (por exemplo, as desigualdades racial, de gênero e outras).

Portanto, parece haver um caminho fértil para mais pesquisas mistas que explicitem as relações entre a exclusão social e a fome, com enfoques diversos (raça, gênero, idade, território etc.) para se poder compreender as especificidades relacionadas a cada grupo e contexto, assim como para mais pesquisas que relacionem a exclusão social à colonialidade do poder na América Latina.

\section{Referências bibliográficas}

ARRUDA, I. K. G. Marcos referenciais da trajetória das políticas de alimentação e nutrição no Brasil. Rev. Bras. Saude Mater. Infant., Recife, v. 7, n. 3, p. 319-326, 2007. Disponível em: $<$ http://pesquisa.bvs.br/brasil/resource/pt/lil-464735> Acesso em: 31 de maio de 2019.

BELIK, W.; SILVA, J. G.; TAKAGI, M.. Políticas de combate à fome no Brasil. São Paulo Perspec., São Paulo, v. 15, n. 4, p. 119-129. 2001. Disponível em:<http://www.scielo. br/scielo.php?pid=S0102-88392001000400013\&script=sci_arttext $>$. Acesso em: $31 \mathrm{de}$ maio de 2019.

COSTA, M. A.; MARGUTI, B. O. Atlas da vulnerabilidade social nos municípios brasileiros. Relatório. 2015. Disponível em: <http://repositorio.ipea.gov.br/handle/11058/ 4381>. Acesso em: 31 de maio de 2019.

DA SOCIEDADE CIVIL, Grupo de Trabalho. para Agenda 2030. Relatório Luz da Agenda. 2018. Disponível em/<http://actionaid.org.br/wp-content/files_mf/1499785232Relatolio_ sintese_v2_23jun.pdf>. Acesso em: 10 de maio de 2019.

DE CASTRO, J. Geografia da fome. Casa do Estudante do Brasil, 1952.

FOOD AND AGRICULTURE ORGANIZATION. An introduction to the basic concepts of food security. Relatório. FAO, Rome, Italy, 2008. Disponível em:<http://www.fao.org/3/ al936e/al936e00.pdf>. Acesso em: 10 de maio de 2019.

FOOD AND AGRICULTURE ORGANIZATION FAOSTAT. Roma, [entre 2016 e 2019]. Disponível em: <http://www.fao.org/faostat/en/\#country/21>. Acesso em: 31 maio 2019.

FRAGOSO, J. Para que serve a história econômica? Notas sobre a história da exclusão social no Brasil. Revista Estudos Históricos, v. 1, n. 29, p. 3-28, 2002. Disponível em: <http://bibliotecadigital.fgv.br/ojs/index.php/reh/article/view/2157>. Acesso em: 31 
de maio de 2019.

IBGE. Pesquisa nacional por amostra de domicílios: segurança alimentar 2004/2009. IBGE, 2000. Disponível em:<https://biblioteca.ibge.gov.br/visualizacao/livros/liv47241. pdf> Acesso em: 10 de maio de 2019.

PERONA, N. Desde la marginalidad a la exclusión social. Una revisión de los conceptos. La Sociología en sus escenarios, n. 5, 2001. Disponível em:

https://aprendeenlinea.udea.edu.co/revistas/index.php/ceo/article/view/7479.

Acesso em: 31 de maio de 2019.

QUIJANO, A. A colonialidade do saber: eurocentrismo e ciências sociais. Perspectivas latino-americanas. Buenos Aires: CLACSO, p. 117-142, 2005. Disponível em: <https:// edisciplinas.usp.br/pluginfile.php/2591382/mod_resource/content/1/colonialidade _ do_saber_eurocentrismo_ciencias_sociais.pdf> Acesso em: 31 de maio de 2019.

QUIJANO. Colonialidad del poder y clasificación social. Contextualizaciones Latinoamericanas, n. 5, 2011. Disponível em:<http://revistascientificas.udg.mx/index.php/ CL/article/viewFile/2836/2574> Acesso em: 31 de maio de 2019.

OLIVEIRA, M. L. M. Geografia da fome: A expressão dramática da desigualdade sócioespacial brasileira. 2013. Dissertação de Mestrado. Universidade de São Paulo. Disponível em: <http://www.teses.usp.br/teses/disponiveis/8/8136/tde-12022014-123610/ en.php $>$. Acesso em: 31 de maio de 2019.

REIS, E.; SCHWARTZMAN, S. Pobreza e Exclusão Social: aspectos sociopolíticos. Versão Preliminar, Relatório, World Bank, 2002. Disponível em: <http://www.schwartzman. org.br/simon/pdf/exclusion.pdf>. Acesso em: 31 de maio de 2019.

RODRIGUES, E. V. et al. A pobreza e a exclusão social: teorias conceitos e políticas sociais em Portugal. Sociologia: Revista da Faculdade de Letras da Universidade do Porto, v. 9, 2017. Disponível em: <https://ojs.letras.up.pt/ojs/index.php/Sociologia/ article/viewFile/2566/2351> Acesso em: 31 de maio de 2019.

SANTOS, L. L. A fome como cerceamento de direito político: comunicação contrahegemônica e soberania alimentar. e-cadernos CES, n. 2, 2008. Disponível em: <https: //journals.openedition.org/eces/1431>. Acesso em: 31 de maio de 2019.

SPOSATI, A. Exclusão social abaixo da linha do Equador. Por uma sociologia da exclusão social: o debate com Serge Paugam. São Paulo: Educ, p. 128-133, 1999. Disponível em: <http://www.seuvizinhoestrangeiro.ufba.br/twiki/pub/GEC/RefID/exclusao. pdf $>$. Acesso em: 31 de maio de 2019.

SOUZA, M. J. L. O território: sobre espaço e poder, autonomia e desenvolvimento. Rio de janeiro: Bertrand Brasil, v. 353, p. 77-116, 1995.

ZANATTA, L. Uma Breve História da América Latina. São Paulo: Cultrix. 2017. 